\title{
SYMPOSIUM J
}

\section{Applications Of Positron Annihilation To Materials Research}

In a series of 19 invited and contributed papers, a group of prominent scientists reviewed the status of positronannihilation research as it applies to materials-science problems. This 1 1/2-day symposium was planned as a means of introducing the concept of the positron as a probe of materials properties. The presentations were grouped into two broad categories. The first addressed the use of positrons to study bulk materials properties, while the second focused on the newly emerging field of variable-energy positron beams, to study surfaces and interfaces.

In studies of bulk properties, Stephen Berko and his colleagues at Brandeis University have shown how information about the electronic structure and Fermi surface of disordered substitutional alloys can be derived from twodimensional angular correlations of annihilation radiation. Furthermore, with the knowledge that positrons are trapped at vacancy-like regions of lower than average electron density, they have extended their investigations to include vacancies, divacancies, and radiation-produced voids. Richard Siegel of Argonne National Laboratory gave further evidence of the value of the positron technique for investigations of point defects and defect clusters too small to be resolved by electron microscopy. This capability has been successfully applied to research related to the important problem of void formation in irradiated alloys.

A second session of invited papers was devoted to descriptions of how variable-energy positron beams can be created and utilized as new probes of surfaces and interfaces. Inasmuch as surface science is one of the most rapidly developing fields of materials research, this session was particularly timely. Karl Canter of Brandeis, Kelvin Lynn of Brookhaven National Laboratory, and David Gidley of Bell Laboratories each described sophisticated new apparatus and recent data covering such diverse phenomena as positron diffraction, positron energy loss spectroscopy, and surface magnetism. Further research efforts in this field are being vigorously pursued by Richard Howell at Lawrence Livermore National Laboratory and Lester Hulett, Jr., at Oak Ridge National Laboratory. It seems likely that the positron will soon join its close relative, the electron, as an important analytical tool for surface scientists.
A.N. Goland
K.G. Lynn
Brookhaven National Laboratory
Chairmen

\section{SAN FRANCISCO}

\section{[Continued from Page 3]}

Materials Engineering at San Jose State University. His principal interests include thin film metallization, phase transformation, and magnetic materials. He has organized numerous special courses and symposia in the Bay Area in the field of electronic materials. He received his Ph.D. in metallurgy from Penn State University in 1964 and since then has performed research at several university and industrial laboratories.

\section{Professional Meeting Managers}

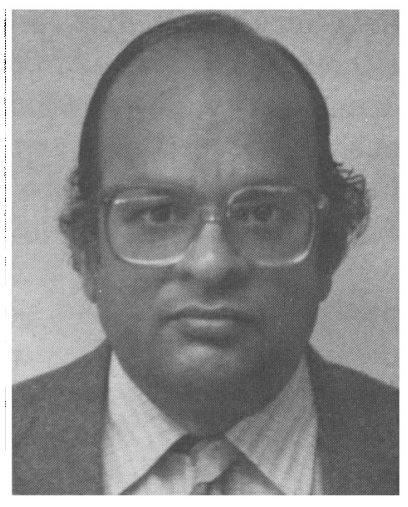

\section{K.S. SREE-HARSHA}

Elton Kaufmann notes, "The MRS has long and successfully relied on volunteer efforts of a large number of scientists in organizing meetings and attending to Society operations, with the support on a part-time basis of an Executive Secretary. The growth and success of the MRS has been due in large measure to the exceedingly high caliber and dedication of those individuals. That volunteerism remains the mainstay of the MRS and will guarantee its future.

"The ever-increasing demands arising from the growth of our meetings, the greater number and variety of member services, and the advent of short courses and equipment exhibit programs have, however, necessitated a more extensive support structure. To that end, our new headquarters with two full-time staff members was instituted. Also, through affiliating with the American Institute of Physics, professional management by the AIP of our equipment exhibits was obtained.

"For the meetings themselves, professional meeting planners have been engaged. This year's Albuquerque meeting was supported by a local company, Albuquerque Meeting Services, through its manager, Judy Eagan. The spring 1985 meeting will be supported by The Complete Conference, a Sacramento-based firm, though its president, Marilyn Hauck, who has also assumed responsibility for hotel relations for the annual fall meetings.

"Implementing these forms of professional support of Society activities will assure greater continuity and efficiency in all Society functions, while permitting our indispensable cadre of volunteers more time to devote to the technical aspects of Society programs," Elton concludes. 